\title{
Recent Developments in Time-Delay Systems and Their Applications
}

\author{
Xian-Ming Zhang \\ School of Software and Electrical Engineering, Swinburne University of Technology, \\ Melbourne, VIC 3122, Australia; xianmingzhang@swin.edu.au
}

Received: 29 April 2019; Accepted: 9 May 2019; Published: 17 May 2019

\section{Introduction}

The last few decades have witnessed the rapid development of networked control systems due to their significant advantages and they have been applied to variant industrial areas such as unmanned surface vehicles, unmanned space vehicles, smart grids, wastewater treatment processes, Internet-based teleoperation, intelligent transportation systems and so on [1-3]. However, time-delays are ubiquitous in networked control systems due to limited network bandwidth and they possibly degrade the closed-loop system performance. The time-delay system approach has been powerful for investigating the effects of time-delays on networked control systems, which is evidenced by several facts such as: (i) a networked control system subject to network-induced delays and packet dropouts can be modelled as a time-delay system; (ii) an event-triggered control system can be modelled as a time-delay system; and (iii) some problems in distributed control systems or multi-agent systems can be transformed into an asymptotic stability problem of time-delay systems. Thus, time-delay systems have been more and more important in modern industrial applications in network environments. On the other hand, the study of time-delay systems has been very active [4]. Since 2001, a descriptor model transformation method, a free-weighting matrix method and an integral inequality approach have been proposed. More specifically, the Wirting-based inequality, which was originally proposed in 2013 [5], has been very attractive and a large number of results on the stability of time-delay systems have been reported in the literature [6,7], which in turn stir up the advanced development of delay-related practical control systems.

\section{The Special Issue}

This special issue received 33 articles but only 11 of them were accepted after peer review. These 11 articles focus on networked control systems, multi-agent systems, variable structure control systems and neural networks with time-delays.

As for networked control systems, some significant issues are addressed: the impact of delays on network-based systems for droop-controlled AC microgrid is investigated in Reference [8]; Tracking control for cloud robotic systems with delayed measurements is considered in Reference [9]; An event-triggered fault detection approach to cyber-physical systems with sensor nonlinearities and deception attacks is presented in Reference [10]; and a non-standard discretization method is introduced to stability analysis of sampled-data systems in Reference [11].

For multi-agent systems, Miao et al. [12] obtain some conditions on $H_{\infty}$ consensus under Markov switching topologies; and Li et al. [13] investigate event-triggered containment control for multi-agent systems with high-order dynamics and input delays. A novel event-triggered sliding mode variable structure control scheme is provided to robustly stabilize memristive systems using a memory-based sliding surface, including the past and the current information of the system states [14]. By employing the Lyapunov functional method, exponential synchronization for inertial neural networks with time delays is investigated in Reference [15]. 
For other issues, a novel algorithm on multifractal detrended fluctuation analysis is proposed and applied to analysis of harmonic multifractal features [16]; Some criteria on finite-time stabilization of stochastic interval systems with time delay are derived in Reference [17] and applied to energy-storing electrical circuits; A nonlinearly modulated Logistic map with delay for image encryption is shown in Reference [18].

These 11 articles collected in this special issue are original works to address some interesting issues appearing in a number of practical systems. The obtained results more or less reflect the effects of time-delays on the related systems, greatly enriching the research in the field of time-delay systems.

\section{Future Research}

The future research on time-delay systems should focus on developing less conservative delay-dependent stability criteria using the canonical Bessel-Legendre integral inequality for various kinds of time-delay systems. Then apply them to investigate both negative and positive effects of time-delay on practical engineering control systems, such as networked control systems, smart grids and wireless robotics and so forth. such that more effective control schemes will be devised.

Acknowledgments: I would like to thank all researchers who submitted their original works to this special issue. I am also grateful to all reviewers who helped evaluate the manuscripts and made valuable and constructive suggestions to improve the quality of articles. I am in debt to the editorial board of Electronics, who invited us to edit this special issue and made great efforts to maintain the rigorous peer-review schedule and to publish these articles on time.

Conflicts of Interest: The author declares no conflicts of interest.

\section{References}

1. Hespanha, J.P.; Naghshtabrizi, P.; Xu, Y. A survey of recent results in networked control systems. Proc. IEEE 2007, 95, 138-162. [CrossRef]

2. Gupta, R.; Chow, M. Networked control system: Overview and research trends. IEEE Trans. Ind. Electron. 2010, 57, 2527-2535. [CrossRef]

3. Zhang, X.-M.; Han, Q.-L.; Yu, X. Survey on recent advances in networked control systems. IEEE Trans. Ind. Inform. 2016, 12, 1740-1752. [CrossRef]

4. Zhang, X.-M.; Han, Q.-L.; Seuret, A.; Gouaisbaut, F.; He, Y. Overview of recent advances in stability of linear systems with time-varying delays. IET Control Theory Appl. 2019, 13, 1-16. [CrossRef]

5. Seuret, A.; Gouaisbaut, F. Wirtinger-based integral inequality: Application to time-delay systems. Automatica 2013, 49, 2860-2866. [CrossRef]

6. Zhang, X.-M.; Han, Q.-L.; Ge, X.; Ding, D. An overview of recent developments in Lyapunov-Krasovskii functionals and stability criteria for recurrent neural networks with time-varying delays. Neurocomputing 2018, 313, 392-401. [CrossRef]

7. Zhang, X.-M.; Han, Q.-L.; Zeng, Z. Hierarchical type stability criteria for delayed neural networks via canonical Bessel-Legendre inequalities. IEEE Trans. Cybern. 2018, 48, 1660-1671. [CrossRef] [PubMed]

8. Zhang, Y. Analysis methodology for evaluation of time-delay impact on network-based system for droop-controlled AC microgrid. Electronics 2019, 8, 380. [CrossRef]

9. Shen, S.; Song, A.; Li, T. Predictor-based motion tracking control for cloud robotic systems with delayed measurements. Electronics 2019, 8, 398. [CrossRef]

10. Li, Y.; Liu, X.; Peng, L. An event-triggered fault detection approach in cyber-physical systems with sensor nonlinearities and deception attacks. Electronics 2018, 7, 168. [CrossRef]

11. Jiang, X.; Yin, Z.; Wu, J. Stability analysis of linear systems under time-varying samplings by a non-standard discretization method. Electronics 2018, 7, 278. [CrossRef]

12. Miao, G.; Li, G.; Li, T.; Liu, Y. $H_{\infty}$ consensus control for heterogeneous multi-agent via output under Markov switching topologies. Electronics 2018, 7, 453. [CrossRef]

13. Li, J.; Li, C.; Yang, X.; Chen, W. Event-triggered containment control of multi-agent systems with high-order dynamics and input delay. Electronics 2018, 7,343. [CrossRef] 
14. Zheng, B.; Fei, S.; Liu, X. Event-triggered and memory-based sliding mode variable structure control for memristive systems. Electronics 2018, 7, 253. [CrossRef]

15. Ke, L.; Li, W. Exponential synchronization in inertial neural networks with time delays. Electronics 2019, 8, 356. [CrossRef]

16. Li, J.; Ma, X.; Zhao, M.; Cheng, X. A novel MFDFA algorithm and its application to analysis of harmonic multifractal features. Electronics 2019, 8, 209. [CrossRef]

17. Chen, G.; Wei, F.; Wang, W. Finite-time stabilization for stochastic interval systems with time delay and application to energy-storing electrical circuits. Electronics 2019, 8, 175. [CrossRef]

18. Li, S.; Yin, B.; Ding, W.; Zhang, T.; Ma, Y. A nonlinearly modulated Logistic map with delay for image encryption. Electronics 2018, 7, 326. [CrossRef]

(c) 2019 by the authors. Licensee MDPI, Basel, Switzerland. This article is an open access article distributed under the terms and conditions of the Creative Commons Attribution (CC BY) license (http://creativecommons.org/licenses/by/4.0/). 